University of South Florida

DIGITAL COMMONS

Digital Commons @ University of

@ UNIVERSITY OF SOUTH FLORIDA

South Florida

Teaching and Learning Faculty Publications

Teaching and Learning

2015

\title{
Exploring Time-lapse Photography as a Means for Qualitative Data Collection
}

Lindsay Persohn

University of South Florida, Ipersohn@usf.edu

Follow this and additional works at: https://digitalcommons.usf.edu/tal_facpub

Part of the Education Commons

\section{Scholar Commons Citation}

Persohn, Lindsay, "Exploring Time-lapse Photography as a Means for Qualitative Data Collection" (2015).

Teaching and Learning Faculty Publications. 533.

https://digitalcommons.usf.edu/tal_facpub/533

This Article is brought to you for free and open access by the Teaching and Learning at Digital Commons @ University of South Florida. It has been accepted for inclusion in Teaching and Learning Faculty Publications by an authorized administrator of Digital Commons @ University of South Florida. For more information, please contact digitalcommons@usf.edu. 
Exploring Time-Lapse Photography as a Means for Qualitative Data Collection Lindsay Persohn, Ph.D.

ORCiD: https://orcid.org/0000-0002-9937-1156

University of South Florida

This is an Accepted Manuscript of an article published by Taylor \& Francis in the International Journal of Qualitative Studies in Education in Volume 28, Issue 5 in 2015. The published article is available at: http://dx.doi.org/10.1080/09518398.2014.915999. 
Exploring Time-Lapse Photography as a Means for Qualitative Data Collection

\begin{abstract}
Collecting information via time-lapse photography is nothing new. Scientists and artists have been using this kind of data since the late 1800s. However, my research and experiments with time-lapse have shown that great potential may lie in its application to educational and social scientific research methods. This article is part history, part theory, and part methodology. As I uncover the science and art of time-lapse, and sort through theory and practice from a number of fields, I share these findings, collect my own time-lapse data, and pose new queries into the use of time-lapse data collection for qualitative and social research.

Keywords: time-lapse photography, qualitative research, social research, reflective practice, teacher inquiry
\end{abstract}


Introduction

In beginning my doctoral studies, I set out to become a better teacher of future educators. I wanted to examine my teaching in action. I naturally thought to video record my class sessions for playback and reflection. After hours spent on processing video to review just ten minutes of my teaching, I realized that it was not a time-feasible method of data collection for my purposes. I also realized that video would not necessarily answer the questions I had about my teaching. I was interested in exploring my teacher behaviours as they were revealed over time. I also realized that I became quickly distracted during the task of watching observational video. I had to watch the video many times in order to answer the questions I had about my teaching, and even then I had difficulty sorting details from overarching themes and patterns. As I planned to study my teaching over time, I began to think about other techniques I could use to speed up the process of observation and analysis, and I re-discovered a lesser-known photographic data collection technique that has not yet seen its full potential as a research tool -time-lapse photography.

Time-lapse photography consists of sequential photographs taken at a set interval (i.e., one photo every second, one photo every 24 hours). Collecting information via time-lapse photography is nothing new. Scientists and artists have been using this kind of data since the late 1800 s. The technique was developed just before motion picture, and time-lapse was in fact the stepping stone from photographs to movies (Solnit 2003). It seems as though it was largely left behind once motion picture became an option. However, my research and experiments with time-lapse have shown that 
great potential may lie in its application to educational and social scientific research methods. This article is part history, part theory, and part research methodology. As I uncover the science and art of time-lapse, sort through theory and practice from a number of fields, and collect my own time-lapse data, I share these findings and pose new queries into the use of time-lapse data collection for qualitative and social research. Accordingly, the purpose of this paper is to share what I learn about the process and application of time-lapse photography techniques in my own social research. I conclude the paper with recommendations for the use of time-lapse photography in social research and with a discussion on future research as related to identified principles of this method.

\section{A Brief History of the Time-lapse Method}

The late 1800 s and early 1900 s were a time of significant change. The 1870 s and 1880s marked the completion of the Transcontinental Railroad and the invention of the Kodak camera, two of many events that notably altered the fundamentals of thought and daily life in America (Solnit 2003). Elsewhere around the world, similar phenomena took place. These new technological advances are examples events that brought significant change in perceptions of movement and time. More people could travel further from home and faster by rail than by horse. The Kodak camera made photographs of everyday occurrences commonplace. Photographs altered popular perception of time, as a likeness of visual images could be preserved for later viewing, giving permanence to fleeting moments. The world was, in a sense, getting smaller; 
great distances could be traversed relatively quickly and pictures could seemingly transcend space and time.

It was during this period that Eadward Muybridge (1830-1904) mastered the technique of photographing moving subjects; fast-moving subjects, when just a few years earlier, the slightest movements during photo exposure would erase the image from its background (Solnit 2003). The English Muybridge worked together with a French master 'picture-taker,' Etienne-Jules Marey (1830-1904), and American railroad mogul Leland Stanford to learn more about the gait of Stanford's winning racehorses (Dagognet 1992, 86-8). Together, this team photographed galloping horses in short sequence and proved a long-standing debate of the time period: Do horses' four feet ever leave the ground at the same time? When these photos proved that a horse's feet did indeed all leave the ground at the same time, the way artists portrayed movement was altered as well, as animals had been portrayed with at least one foot on the ground at all times, even while in motion. It is clear that Marey and Muybridge followed each other's work, but unclear as to who first developed the technique. Nevertheless, this joint effort of the minds and Stanford's money refined the cosmos of scientists and artists alike. These motion studies are considered the precursor to motion pictures as we know them today (Solnit 2003). Muybridge and Marey used time-lapse photography first to slow time, so motion could be examined more closely. The inverse of this technique could be used to speed time, capturing a series of images at longer intervals, and making larger movements more apparent. 


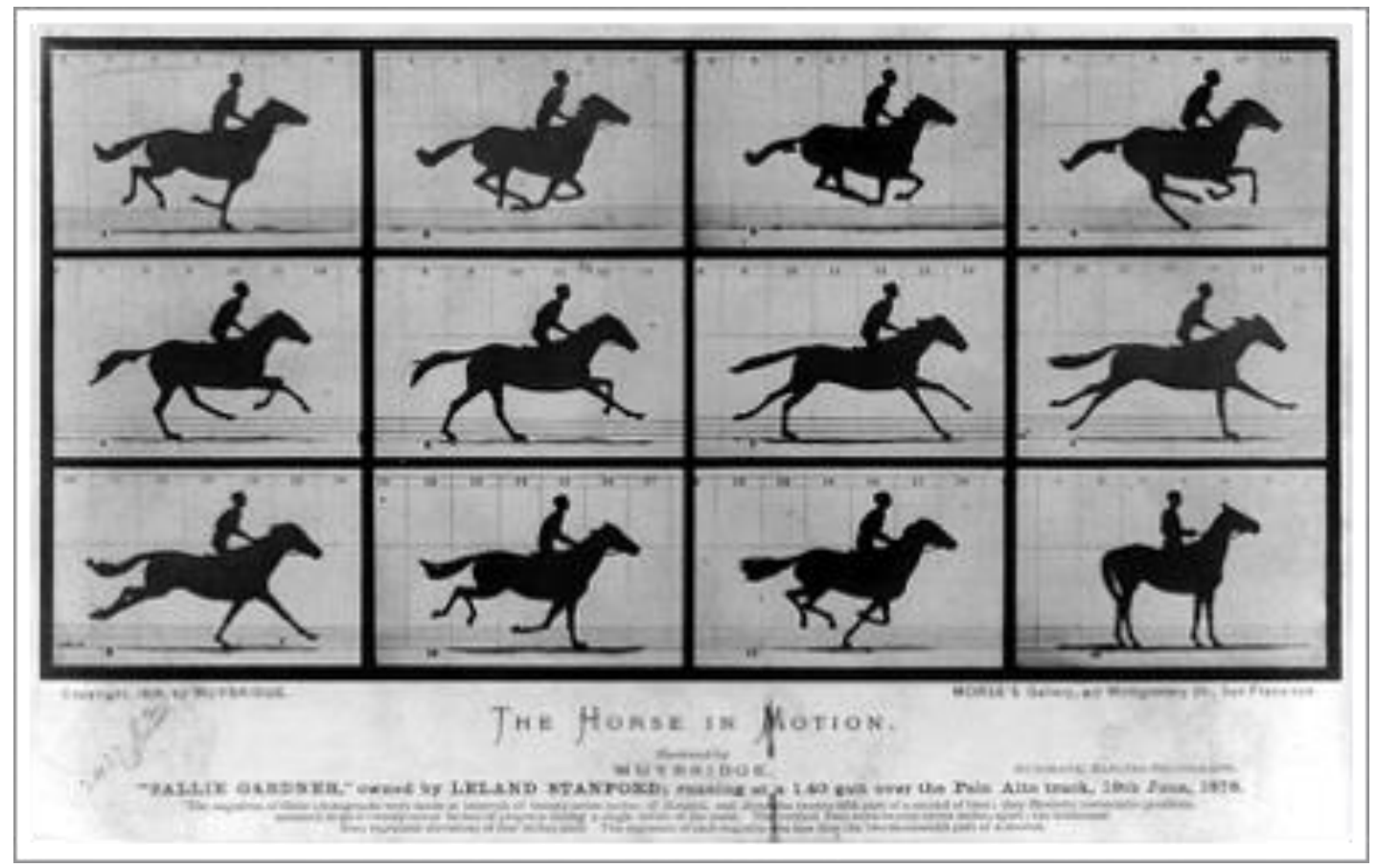

Figure 1: "The Horse in Motion" (1878) - Arguably the most well known of Muybridge and Stanford's motion studies. Retrieved from http://www.loc.gov/pictures/resource/cph. 3a45870\%.

A half a century later, John Ott (1909-2000) used a time-lapse method to uncover much of the unknown world of plants (Ott 1958). He initially worked with equipment that he built by modifying the family's kitchen clock to create a timer for his camera. He changed plant environments and studied the effects to determine which plants responded best to direct sunlight, and which grew better in filtered sunlight. He saw changes in plants that were not observable in real time by photographing plants at extended intervals, making the patterns in growth of plants evident. He went on to study how light affects the well being of people, the beginnings of what we know now about ultraviolet or infra-red rays (Ott 1973). One other notable aspect of Ott's research is that he used time-lapse photography in conjunction with a microscope, greatly narrowing the focus of the lapsed event. 
In the field of education, in the 1950s, Withall (1956) utilized a time-lapse methodology to quantitatively study an art teacher's interactions with students. Timelapse photos were taken every fifteen seconds during an eighth grade art class for twelve weeks. Withall (1956) sought to understand how the teacher's time was distributed among students, to what extent the amount of time spent with each student differed, and whether or not the amount of time spent with each student was consistent with his or her presumed needs. He found that the teacher's time was not evenly distributed among the needs of his twenty-six students, even after the teacher made a conscious effort to balance interactions.

In the late 1800 s and even in the 1950s, photographs were expensive to take, the process was long, and photography equipment was large, cumbersome, and fragile. The idea of creating a sequence of photographs, then studying the photos in succession was well ahead of the technology available to support it. Now, the equipment is lightweight and easily operated, and digital photography makes the process fast and efficient. My study begins with the kernel of thought from Muybridge's motion studies and expands on Withall's ideas about teaching observations, with time-lapse footage taken at shorter intervals over a longer period of time, through a lens for the qualitative attributes of teaching.

\section{A Formative Experiment in Time-Lapse as Method}

Based on my experience and preliminary research, I believed the time-lapse method could help me identify patterns in social situations that are longer in duration than those apparent under the constraints of our natural perception time. At the start of 
my own time-lapse documentation, my questions dealt with my direct instruction, my indirect instruction and the semester-long outcomes of my teaching. In particular, I was interested in my use of arts-integration in teaching pedagogy, and the overall aesthetic conditions I created within our classroom context. I teach undergraduates in a large university teacher education program in the Southeastern United States. In the first of the courses I studied, Teaching Literature in the Elementary School, I taught 25 students in a sterile-looking classroom that serves as teaching and learning space for many other classes throughout the week. As the semester unfolded, patterns emerged in our meetings, patterns that may have gone unnoticed had I not examined time-lapse footage of my teaching. I captured time-lapse photographs of each class session, then transferred the photos to my computer's movie making program, and watched the photos back in rapid sequence.

I found that the process of creating a time-lapse movie almost easy. My camera is made specifically for taking time-lapse photos. It is simple and durable, as it is built for use outdoors in gardens to observe plants and animals. It cost about a hundred dollars and I bought it online. The purchase of tripod and a memory card brought my total investment in equipment up to about $\$ 175$. In my search for the equipment, I found that some regular digital cameras had an available attachment that could be set to repeatedly take photographs at specified intervals. I was able to use the desktop computer I already had to create my time-lapse movies. As time went on, and as my collection of photographs grew, it became necessary to purchase an external hard drive for photo storage and backup. 
My typical process for time-lapse movie creation was rather simple. After I powered my camera on and set it to frame the scene I wanted to examine, I taught my class. As I packed my things, I powered down the camera and dropped it in my bag. At my computer, I opened iMovie, changed a few settings in a new project, plugged the camera in to my computer, and imported the photos from the event. The import generally took about 30 minutes (for a 3 hour class session that has been photographed every 10 seconds). It took about 15 minutes to watch at a rate of 1 second per image if I allow time to visually scan each photo. I sometimes watched a class in as little as 2 minutes, at just 0.1 second per image, if I was looking for less subtle phenomena.

Because of the way the classroom furniture and audiovisual equipment was set in the room, the camera placement for this project was fairly natural. I wanted to capture the area in which I delivered most instruction. My challenge was to find a surface on which to place the camera where it was unobtrusive to my students' activities and provided a wide enough view of the area where I would deliver the majority of instruction. A table in the back corner of the classroom became the typical place for the camera each class meeting. My choice to photograph my instruction every 10 seconds worked well with the logistics of the photographs and the images I wanted to capture. I found that in the scheme of a three hour class meeting, the inherent changes in activity, conversation, and physical environment were perceivable in the ten seconds between photos. More specifically, I detail below my first four time-lapse data collection sessions in the previously described context.

Implementation (Time-Lapse 1) 
I set up my time-lapse camera side by side with a video camera for my first trial (See figure 2). I wanted video footage that corresponded with the time-lapse photographs I captured so I could later analyze the time-lapse details, benefits, and shortcomings with a video of the same experience. I framed the front of the classroom in the viewfinder, to capture my slide presentation and the conversations centered around it. Once I turned the cameras on, I hoped to forget they were there for the next few hours of film time and teach my class as naturally as possible.

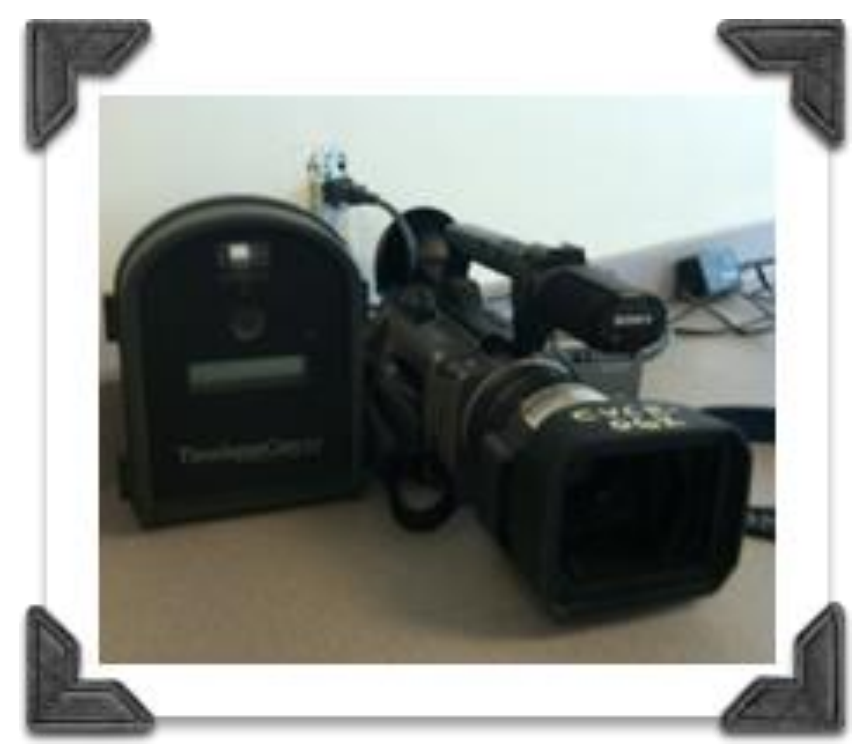

Figure 2 - The set-up of my time-lapse camera and a borrowed video camera. Video footage was taken alongside time-lapse footage for later analysis.

At my computer later that evening, I opened my movie-making program (I use Apple's iMovie), removed the photograph transition effects from my new project, and dropped the 889 photographs I had taken that day into my project timeline. Once the 
photos transferred, I was able to immediately play the 'movie' I created. By removing the photo transition effects, iMovie seamlessly advances from one sequential photograph to the next, displaying each photo for the duration that I specify in the project settings. Together, the photos read as a movie made of still images, as with stop-motion animation. The finished product evoked thoughts of a flip book. If these photos were printed and bound on one side, then quickly 'flipped,' a result similar to a time-lapse movie would be achieved. Just like the flip book, photos can be 'flipped' quickly or slowly, depending on the level of detail suitable for the line of inquiry and paused anytime for closer consideration.

When I viewed the time-lapse movie I created for the first time, I noticed several benefits in this methodology over video in answering my questions. I found it easy to recall the events of the class at any given time with still photos and moving photos as visual prompts. It was as if I had taken visual notes. I was able to distinguish which events and conversations I deemed important in my reflexive inner conversation about the time-lapse movie. Patterns in events were more easily discerned. I was able to quickly see the relative amount of time my students sat listening to me speak, the amount of time students interacted with each other in small group settings, and the amount of time students spent moving about the classroom versus sitting still. I could more easily identify the topics of conversation as I realized that specific dialogue is often forgotten and spoken sentences are often left incomplete (Vygotsky 1962). The timelapse technique conveyed less instantaneous qualities of the class session, like which conversations and activities appeared most engaging for students, while still allowing me to examine details by isolating individual photographs. 
It was at this point I realized that I tend to view typical video playback of myself quite critically, focusing on the brainless mistakes I make and judging my every move. For me, this has not been particularly productive in improving my instruction. In video playback, I viewed myself, the teacher, though a hypercritical lens when my focus may have been more productive had I focused on the teaching (Hiebert \& Morris 2012). The time-lapse movie helped me to move away of this negative and one dimensional way of thinking, to take a step back from the situation, to see deeper meaning in my actions and the way I visually portray ideas in my classroom. Additionally, video was not a timefeasible method for reflection on my teaching. This course met for three hours a week for a sixteen week semester. Three hours of video a week would take a minimum of three hours of playback time, with additional time for playback of points of interest. In anticipation of viewing all class meetings upon the semester's conclusion, 48 hours of video data would have been overwhelming and was unlikely to help me find the answers to my questions.

A later viewing of this first movie generated other notes of interest. I thought about how and where to insert new ideas I had about arts-integrated teaching. For the majority of class sessions in this particular course, Teaching Literature in the Elementary School, we practice Sustained Silent Reading (Lynch-Brown and Tomlinson 1999; Rosenblatt 1995; Trelease 2001), participate in literature circles (Daniels 1994), read aloud to each other (Rosenblatt 1995; Trelease 2001), and address the characteristics of a particular genre (Kiefer 2010). I wanted to share action rhymes with my class to incorporate more poetry into our day and give teachers a tool to use for the management of classroom transitions. The time-lapse movie helped me to find a point 
in the cycle of our class day that seemed to be a natural fit for introducing an action rhyme. The value of an action rhyme is most obvious if used to transition from a noisy activity to a quiet one. Even without a sound recording, I was able to see which activities in the class were quiet and which facilitated verbal interaction and movement, making it easy to identify the best place to incorporate this kind of transition activity. I successfully incorporated a transition rhyme between literature circles and the next activity on our agenda during the class meeting following this realization.

Second Attempt (Time-Lapse 2)

In my second time-lapse movie, I discovered that I made a serious error in the placement of the camera. The footage was not useful for its intended purposes of capturing my teaching. I could not see much; just the movement of the top of my head and the changes in the top of my presentation slide.

However, with a new set of photographs, and now a few spare moments, I explored other technical possibilities with time-lapse movies. I changed each frame's duration in the movie sequence with a few clicks in the project settings. By clicking the settings box in the bottom left corner of any photo in the project, I could adjust the clip duration, then click a check box to apply the new settings to all of the still photos in the project. With this small adjustment, I altered the settings of my three hour class movie to condense about 15 minutes (at 1.0 second per frame) to less than two minutes (at 0.1 seconds per frame). In this case, when much of the footage was very similar (the top of my head and an insignificant portion of my presentation slides), I focused on a different aspect of the technique to get a sense for how drastically I could manipulate time with 
this technique and the speed and simplicity of the process. This proved useful in answering later questions. This error in camera placement also made me more mindful of my camera angles and more cautious to frame the front area of the room where I often delivered instruction.

Modification (Time-Lapse 3):

The third time I used this method to document my own teaching was quite different from the first and second movies because, during this class period we took a field trip to our campus library. My students crossed the lawn to a library computer lab, where they searched for books that interested them from the course text, then located those books on the library shelves. Of all of the thoughts I had about how to take the camera with us to the library, it seemed most logical and possibly most productive in documenting the trip if I carried it in my hand. This task was naturally made more difficult by the amount of materials I typically bring to a class. I realized how many times I shifted my things while moving around the classrooms, hallways, elevators, and outdoors. (These observations proved useful, as I began to find new ways to lighten my load.) That evening, I had 836 still photos, and in about a half an hour of photo import time, I had the 14 minute version of the day's class session. The pace was sufficiently slow when I set the duration for each time-lapse photograph at one second per frame; I had more than enough time to scan each photo and feel as though I could recall what was going on in the picture. I could recall what we were talking about and some of the more important questions that were asked. 
As we migrated from the classroom to the library, I realized how many spaces I had entered and exited in less than three hours. I began to list in my mind, and then on paper, all of the spaces (i.e., rooms) I remembered entering or exiting. Then I watched the rest of time-lapse movie. My list from memory was missing nine additional spaces that the time-lapse movie revealed. The details in the photographs made me realize that the library lobby and the circulation desk area are really two separate spaces. The lighting is different, the flow of traffic is different, and they serve different purposes. The time-lapse movie framed my view differently than I had framed it myself in the 50 or 100 other times I had physically entered the library. Because my view was limited by the camera angle and stillness, I paid attention to different elements than I had in person, which led me to believe that time-lapse had the potential to change the focus of my observation in other ways as well. The lighting and colouring became the important elements in some photos periodically. In other photos, the movement was the most important element of the picture. I had forgotten that I stopped by my office on my way to the library from the classroom to drop off a file box. The time-lapse movie jogged my memory to recall that the door to the computer lab had been locked and I had to run downstairs to get a key. (With a few simple computations, I could tell you how long it took me.) I had not recalled these details in my reflection of the day without the visual prompts of my time-lapse movie. Though these are not in and of themselves lifechanging observations, I learned how the use of time-lapse photography could change my focus and perspective, and how quickly I could view and re-view the time-lapse footage with attention to different elements. 
For this third time-lapse artifact, I changed my camera settings to include a time and date stamp on each photograph. This stamp also includes the 'name' of the camera (a name I have given it) and the photo interval (in this case 10 seconds). I found that the time and date stamp helped me to reorient my sense of time at this accelerated pace, as I could easily observe the passing of each minute of real time.

Modification 2 (Time-lapse 4):

While watching this movie playback, I still focused on the dialogue that I remembered at each point. It was easy for me to tell when the topic of dialogue changed. This, I believe, was due in part to the fact that I was obviously in the room when the photos were taken, but also due to what I saw in the time-lapse movie. The change of a presentation slide, the physical adjustments of my students in their seats, and the movement of my students to a new space in the room to carry out another task were all clear shifts in the center of conversation. It can be difficult to find a balance between activity and stillness in order to accommodate those students who need to be mobile during a class meeting versus those who are quiet and introverted learners. I wondered how many times my students moved to new centers of dialogue during the course of the class meeting. I adjusted my movie settings to display each photograph for a half of a second, making the movie just over 7 minutes long, and proceeded to watch for activities that caused my students to re-center their conversations. I found that while quantifying their shifts on paper, I had time to spare. So, I adjusted the settings to display each photo for 0.1 of a second, creating a movie that was just under 2 minutes. This pace allowed me to accurately count the number of times our agenda caused a 
shift in conversation. I realized that the shifts in space varied in degree, and this point was made plain through the quickest time-lapse movie. My students moved across the classroom to pick up a book to read to themselves and evaluate, an inner dialogue. Later in the class period, we all traveled from the fourth floor of the education building to the first floor to use the computer lab. There were hallway conversations and dialogue about library catalog searches. From there, we traveled even further, outside of the College of Education, and to the fourth floor of the library to find children's books. This particular focus as I reviewed my footage revealed that there were both times of activity and times of quiet during the class period. This observation helped me in planning subsequent classes, as I attended to the degree in shifts of conversation when outlining a class agenda.

My time-lapse data collection is ongoing in different physical classroom contexts, as well as different course material contexts. Conversations with my students reveal that they notice a flow to our class meetings, each time we meet, as well as over the semester. Time-lapse helps me to understand through visual cues, how to craft a class meeting in a way that is cohesive in content, yet varied in form. As I reflect on each semester, I find that I teach with more intention than I have in the past, as time-lapse has given me the tools to understand where instruction has been as well as where it is going, on a grander scale. Since initiating the use of time-lapse, I have given more attention to the sequence of events in each class meeting and the ways in which ideas unfold and build upon each other over time. I used the footage from the first semester when planning the following semesters. I was able to examine the flow of ideas 
throughout a class meeting and the semester, cut down on squandered transition time between activities, adjust the focus of discussions that became too long to keep students' attention, and develop routines in class meetings that students reported helped them navigate class proceedings with comfort. More recently, I have shown time-lapse footage to my students as a review for previous classes, to review discussions and call for remaining questions about our topics.

\section{Discussion}

John and Malcolm Collier (1986) address the analysis of photographic images. They affirm that visual evidence must be "contextually complete and sequentially organized" (p. 163). Time-lapse is, by nature, sequentially organized, as photographs are taken at equal and set intervals. Time-lapse footage allowed me to review the context of an entire class session and, later, an entire semester of class sessions in a single sitting. Though the context of these time-lapse photos is limited by the space and movement represented in the photographs, I am able to gain a more complete sense of how I present ideas in the classroom over time.

Analysis of my time-lapse footage began with the decoding of photographs, a process in which I reduced my thoughts about the tangible and intangible elements of a class session to written words in a reflective journal (Boud, 2001). These initial thoughts helped me to see my teaching from an outsider perspective, all the while maintaining what I knew about the broader context of the course from my first-hand experience teaching the class, interacting with my students, and understanding the objectives of the course from a program-wide perspective. As indicated by Collier and Collier (1986), 
some of my thoughts could not be expressed in words, as they were embodied in the actions, behaviours, and emotions represented by the movement captured in still images. It is worth noting that time-lapse is less valuable for recall of specific phrasing and verbatim analysis. However, in the case of nonverbal teaching behaviors, this method helped me to answer many questions I had about my body language, spatial orientation, and pacing made visible through the images in these photographs.

Phenomena revealed over time through visual cues, or visual cycles and patterns that are slow to repeat, can be difficult to identify (Reinking and Bradley 2008, 50). For example, the growth of a plant or the construction of a new building represent instances of phenomena that slowly develop in time and space. I have found that these, and other elusive circumstances (such as teaching in my case), become more apparent through a systematic trimming of scenes that become less consequential when looking at time through an expanded lens.By using time-lapse photography, allowing time to elapse naturally and capturing photographs at set and equal intervals, I learned that the editing of scenes is systematic and impartial. Throughout my trials with time-lapse, I gathered details from my own experience and from the work of others in an attempt to better articulate the use and application of this method to social research. Throughout this discussion, I will attend to aspects of this methodology that may be useful to qualitative researchers based on my particular experiences and existing literature.

\section{Sensory Deprivation}

By capturing sequential still images, my focus in playback was on elements that were new to my way of thinking. I saw details that I did not notice in the moment, and 
details that were not evident in other videos I have analyzed of my teaching. I found that the absence of sound in time-lapse photography is an asset. One of the first things I noticed as I watched the first time-lapse movie of my teaching: I was able to attend to the visual elements of the movie and have an inner dialogue with myself as I watched. I could easily recall the topic of conversation, an approximation of what I was thinking at the time, and what I could have done differently in hindsight. It has been noted that nonverbal communications can be quite difficult to study, as there are many factors to explore simultaneously (Galloway, 1974). The time-lapse movie served to jog my memory, and I was able to capture my thoughts in words and on paper without the static of conversation. I was able to attend to nonverbal communications, which I had often missed in video analysis or reflection from memory of my teaching. I also realized that the properties of sound would render audio unintelligible at the speed of time-lapse movies. This may be useful to other qualitative researchers considering data collection through time-lapse photography because it helps to identify research questions that are potentially answerable through time-lapse.

Focus

During my own time-lapse trials, I also realized that I could use time-lapse to see things that were quite small in scope, or I could take a much grander view. I could attend to the patterns in my movement around the classroom, or to just my hand gestures at the front of the room. Then I realized that Eadward Muybridge and John Ott taught me this: Muybridge, with his ingenious human and animal movement photographs (Solnit 2003), and Ott (1958) with this microscopic time-lapse of plant 
growth. Muybridge published groundbreaking photo books at the turn of the twentieth century that forever changed the way movement is tracked over time and animal locomotion for the sake of its physical aspects (i.e. Muscle movement, flight patterns, etc. (Muybridge 1899, 1901)).

In my own data collection, framing of the camera was important. Since my teaching behaviors were the focus of the study, I framed the front of the classroom, where the podium, computer, and projection screen were located. Many times, I was out of the camera's view as I circulated through the room to talk with individual students or small groups while they worked. Yet, I was able to tell how many times I circulated the classroom and which direction I moved. Several of my teaching spaces were not conducive to this project, because of the room size, room shape, or availability of furniture on which to place the camera. With the small, battery operated camera, I was able to find a satisfactory solution to placement. The ability to mount the camera near the ceiling may have given me a better overall picture of classroom interactions. As I reviewed an abundance of visual data collected throughout the semester, I noted the importance of creating a purposeful sample within the natural limitations of the camera's lens.

\section{Altering Time}

Time-lapse movies allow for the alteration of time. Hours can be summarized into minutes, years can become hours. Altering the photo intervals and adjusting the display time for each frame presents seemingly endless possibilities in our ability to change the pace of time. In my research, one photo every ten seconds worked well to capture the 
activities in the classroom. By thinking about the pace of changes in the classroom, I decided on this setting. Though some activities unfold relatively quickly in a college classroom, others unfold slowly. Six photos per minute provided a detailed view of classroom proceedings, while speeding time in observation. Observation of other phenomenon in social research may require photos at more frequent or extended intervals, depending on the pace of change in activity in the particular circumstance.

In my study, sensory deprivation, focus, and the altering of time proved valuable in improving my instruction. For example, during my fifth class session, I ran out of time before reading aloud to the class. At the beginning of the course, I stressed to my students how important consistent reading aloud is in the development of students' reading skills (Trelease, 2001). Naturally, I wanted to be sure that I did not just tell students that reading aloud is important; I wanted them to experience it themselves. Running out of time for a read aloud was not acceptable. I viewed the time-lapse movie with a specific question in mind: What could I do differently to ensure I read aloud to my class every time we met?

Through a review of the class time-lapse movie, I identified a portion of class that could be done more easily by my students at home. Typically, we stopped by a computer lab so students could search the library catalog before going to the library to choose books for the upcoming weeks' genre study. Since we had searched the library catalog together several times, I was confident that my students could now conduct the search on their own and bring the call numbers to class. When I shared the idea with 
my students, they agreed, and expressed that they, too felt we were squandering class time with a catalog search during class. This change in my instruction reclaimed at least twenty minutes of class time. Based on the length of my typical read aloud (as figured by averaging read alouds from multiple time-lapse sequences) I could rest assured that I would consistently demonstrate the importance of read alouds in future class meetings.

The example above and other similar scenarios I encountered during my experience, served to affirm my feeling that social and qualitative researchers could gain insights from examining time-lapse images, and the movies that can be made by seamlessly connecting those images. Not only can researchers examine changes in physical spaces over condensed sequences of time, but can also track visible social changes in a shortened span. If a picture is worth a thousand words, then thousands of sequential pictures are a narrative gold mine.

In my experience with time-lapse as a data collection method, I could isolate specifics in an event while drastically increasing the rate of playback speed. Not only was the playback time systematically reduced, the overall time invested in the project was significantly less than any video observation I had ever conducted. When I video recorded ten minutes of my teaching, transferred the footage to my computer and watched it back, the process took nearly six hours and required a large amount of digital storage space. The first time I captured time-lapse photos of three hours of teaching, transferred the photos to movie format, and played the movie while making notes of my findings, the whole process took less than an hour (See Figure 3). 


\begin{tabular}{|l|c|c|c|c|c|}
\hline & $\begin{array}{c}\text { Time-Lapse } \\
\text { \#1 }\end{array}$ & $\begin{array}{c}\text { Time-Lapse } \\
\text { \#2 }\end{array}$ & $\begin{array}{c}\text { Time-Lapse } \\
\text { \#3 }\end{array}$ & \multicolumn{2}{|c|}{$\begin{array}{c}\text { Time-Lapse } \\
\# 4\end{array}$} \\
\hline Total time of photo capture & $2 \mathrm{~h}, 58 \mathrm{~m}$ & $2 \mathrm{~h}, 33 \mathrm{~m}$ & $2 \mathrm{~h}, 46 \mathrm{~m}$ & \multicolumn{2}{|c|}{$2 \mathrm{~h}, 52 \mathrm{~m}$} \\
\hline Time elapsed between photos & $10 \mathrm{~s}$ & $10 \mathrm{~s}$ & $10 \mathrm{~s}$ & \multicolumn{2}{|c|}{$10 \mathrm{~s}$} \\
\hline Total number of photos captured & 889 photos & 765 photos & 836 photos & \multicolumn{2}{|c|}{885 photos } \\
\hline Duration of exhibit of every & $1 \mathrm{~s}$ & $1 \mathrm{~s}$ & $1 \mathrm{~s}$ & $0.5 \mathrm{~s}$ & $0.1 \mathrm{~s}$ \\
\hline Total movie length & $14 \mathrm{~m}, 49 \mathrm{~s}$ & $12 \mathrm{~m}, 45 \mathrm{~s}$ & $13 \mathrm{~m}, 56 \mathrm{~s}$ & $7 \mathrm{~m}, 22 \mathrm{~s}$ & $1 \mathrm{~m}, 58 \mathrm{~s}$ \\
\hline
\end{tabular}

Figure 3: A comparison of the technical elements of my time lapse capture.

Note: All of the photos for these projects were taken with Wingscapes 8.0 Timelapse Cam. All movies were made on a 27" iMac with iMovie.

\section{Further Research}

I still have many questions about the use and value of time-lapse methods for data collection and analysis of educational experiences. I wonder how much time-lapse footage means to someone who has not experienced the phenomena. I wonder what others would see if they watched the same footage without the advantage of the lived experience to draw upon. I wonder what researchers in other fields could glean from time-lapse data of their subjects of study.

Throughout this process, I grappled with questions about how this method is similar to and different from video recording. My studies thus far have revealed that these two methods serve quite different purposes. One is not a replacement for the other; they are separate options for data collection. One is not overall better or worse than the other; they serve different purposes. Video is necessary for collecting specific 
details, while time-lapse is necessary for collecting non-specific details. Video is necessary for recording sounds as well as visuals, while time-lapse collects photographic visuals that can be summarily narrated. Time-lapse footage has the potential to be used as a map of sorts for video data. I feel that this is a topic that still merits deeper consideration.

In the field of teacher education, mentor teachers and interns could watch the school day back in minutes, prompting conversation about the high and low points. In the education of pre-service teachers, time-lapse footage of talented in-service teachers could be used as a teaching tool by college instructors, it would be feasible to use clips of time-lapse as a prompt for class discussion. An entire school year could be systematically edited to a few hours, so long patterns of activity could be more easily identified. The focus shifts from the person (the teacher) to the process (the teaching) (Hiebert \& Morris 2012). I continue to study my own teaching through time-lapse and have begun to analyze longitudinal data over several semesters and varying courses to mine for data about my specific teaching behaviours over time and across course content.

More specifically, I see strong applications in the documentation of case studies. Dyson and Genishi (2005) authored a fundamental volume on using case study in literacy research. They 'of course, support systematic ways of doing research that are carefully detailed, whether we are documenting what participants are doing or reflecting on our own research practices' (p. 56). A time-lapse camera could help to photographically document the study, without unmanageable amounts of footage and equipment. Time-lapse would work well in a noisy research environment, where sound 
would not be helpful regardless. Dyson and Genishi (2005) talk of their questions about how to capture audio in a preschool classroom. They concluded that it was difficult to hold an audio recorder while focusing on observations and notes; even if they managed to capture the audio, it would be nearly impossible to isolate any of the sounds with the natural volume of a preschool classroom (p. 64). In the report from this same case study, they mention that in order to capture the 'fine-grained details' they use three kinds of information to construct field notes: copies of children's products, scratch notes, and audiotapes. If a strategically placed time-lapse camera were added to that data source toolkit, photographic data could be added to that list. Along these same lines of thought, ethnographic and semiotic researchers may find the same value in systematic photographic data.

The time-lapse method could be used to document and examine a wide array of physical changes that reveal themselves visually over time. Now that the notion of timelapse and the technology to produce it have come to a bit of a crossroads, the method is inexpensive and fairly easy to use. The use of time-lapse photography in the context of social research calls for considerable further exploration given its demonstrated promise through this research. 


\section{References}

Barretto, R. P. J., Ko, T. H., Jung, J. C., Wang, T, J., Capps, G., Waters, A. C., Ziv, Y., Attardo, A., Recht, L., \& Schnitzer, M.J. (2011). Time-lapse imaging of disease progression in deep brain areas using fluorescence microendoscopy. Nature medicine 17 (2): 223-8.

Boud, D. (2001). Using journal writing to enhance reflective practice. New Directions for Adult and Continuing Education (90): 9-17.

Braun, M. (2010). Eadweard Muybridge. London: Reaktion Books.

Coleman, T. A., Knupp, K. R., \& Herzmann, D.E. (2010). An undular bore and gravity waves illustrated by dramatic time-lapse photography. Journal of Atmospheric \& Oceanic Technology 27 (8): 1355-61.

Collier, J. \& Collier, M. (1986). Visual anthropology: Photography as a research method. Albuquerque: University of New Mexico Press.

Connor, S. (2004). Edison's teeth: Touching hearing. In Hearing cultures: Essays on sound, listening, and modernity, edited by V. ErImann. London: Berg Publishers.

Crowther, B. (1956, Nov 1). Screen: 'Secrets of Life'; Disney True-Life Adventure, at Sutton, Observes Nature With Zest. The New York Times. Retrieved from http://movies.nytimes.com/movie/review?res=9C03E6DA1230E23BBC4951DFB

\section{D649EDE.}

Dagognet, F. (1992). Etienne-Jules Marey: A passion for the trace. (R. Galeta and J. Herman, Trans.) New York: Zone Books. Original work published 1987.

Daniels, H. (1994). Literature circles: Voice and choice in the student-centered classroom. York: Stenhouse Publishers. 
de Mol, J., Burnett, M., Morrissey, A., Bakkers, S., \& Metzger, L. (2012). February 5, 2012. The Voice. Los Angeles: National Broadcasting Company.

Dyson, A. H. \& Genishi, C. (2005). On the case: Approaches to language and literacy research. New York: Teachers College Press.

Galloway, C.M. (1974). Nonverbal teacher behaviors: A critique. American Educational Research Journal 11(3): 305-306.

Golparvar-Fard, M., Pẽna-Mora, F., \& Arboleda, C.A. (2008). Visualization of construction progress monitoring with 4D simulation model overlaid on time-lapsed photographs. Journal of Computing in Civil Engineering 23 (6): 391-404.

Hibler, W. (1956, Nov 6). The secret life of plants. In Disney's secrets of life: Volume 4. [Motion picture]. Disney studios.

Hiebert. J. \& Morris, A. K. (2012). Teaching, rather than teachers, as a path toward improving classroom instruction. Journal of Teacher Education 63 (2): 92-102.

Hillman, P., Hannah, J., \& Rental, E. (2005). Semi-automatic foreground/background segmentation of motion picture images and image sequences. Vision, Image and Signal Processing 152 (4): 387-97.

Kiefer, B. A. (2010). Charlotte Huck's children's literature. Boston: McGraw -Hill.

Lyman, R. (2002, August 18). Cameras to record ground zero rising, a frame at a time. New York Times, 1.

Lynch-Brown, C. \& Tomlinson, C. M. (1999). Essentials of children's literature. Boston: Allyn and Bacon.

Muybridge, E. (1893). Descriptive Zoopraxography. Available from 
http://www.amazon.com/Descriptive-zoopraxography-science-locomotionpopular/dp/114934220X.

Muybridge, E. (1899). Animals in Motion. Available from http://www.amazon.com/Animals-Motion-Dover-AnatomyArtists/dp/0486202038/ref=sr 1 1?s=books\&ie=UTF8\&qid=1330072009\&sr=1-1.

Ott, J.N. (1958). My ivory cellar; [The story of time-lapse photography]. Old Greenwich, CT: The Devin-Adair Company.

Ott, J. N. (1973). Health and light: The extraordinary study that shows how light affects your health and emotional wellbeing. New York: Pocket books.

Persaud, B., \& Hurdle, V. O. (1988). Freeway traffic data from time-lapse film. Transportation Science, 22: 251-7.

Reinking, D. \& Bradley, B. (2008). On formative and design experiments: Approaches to language and literacy research. New York: Teachers College Press.

Rosenblatt, L. M. (1995). Literature as exploration. New York: Modern Language Association.

Solnit, R. (2003). River of shadows: Eadweard Muybridge and the technological wild west. New York: Penguin.

Trelease, J. (2001). The read-aloud handbook. New York: Penguin.

Vygotsky, L. S. (1962). Thought and language. Cambridge: The M.I.T Press.

Withall, J. (1956). An objective measurement of a teacher's classroom interactions. The Journal of Educational Psychology 47 (4): 203-212. 